Research Article

\title{
Ceria-Based Mixed Oxide Supported Nano-Gold as an Efficient and Durable Heterogeneous Catalyst for Oxidative Dehydrogenation of Amines to Imines Using Molecular Oxygen
}

\author{
Bashir Ahmad Dar 1, Meena Sharma 2, Baldev Singh 1* \\ 1 Indian Institute of Integrative Medicine (CSIR), Canal Road, Jammu, India-180001 \\ 2 Department of Chemistry University of Jammu. (J \& K), India-180004
}

Received: 26th December 2011; Revised: 7th June 2012; Accepted: 13 rd June 2012

\begin{abstract}
The present work is intended to determine the catalytic activity of Mixed Oxide supported gold for aerobic oxidative dehydrogenation of amines to imines using Ceria as a main constituent of the each support. The model catalysts $\mathrm{Au} / \mathrm{CeO}_{2}: \mathrm{TiO}_{2} \mathrm{Au} / \mathrm{CeO}_{2}: \mathrm{SiO}_{2}, \mathrm{Au} / \mathrm{CeO}_{2}: \mathrm{ZrO}_{2}$ and $\mathrm{Au} / \mathrm{CeO}_{2}: \mathrm{Al}_{2} \mathrm{O}_{\mathrm{s}}$ were prepared by deposition co-precipitation method and deposition of gold was determined by EDEX analysis. The supported nano-gold catalyzes the dehydrogenation of secondary amines to imines without loss of activity. On recycling good amount of product yield is obtained. Oxidation of secondary amines to imines is carried at $100^{\circ} \mathrm{C}$ and almost $90 \%$ conversion was obtained with $>99 \%$ selectivity. (C) 2012 BCREC UNDIP. All rights reserved
\end{abstract}

Keywords: Heterogeneous Catalyst; Nano-Gold; Metal Oxides; Imines

How to Cite: B.A. Dar, M. Sharma, B. Singh. (2012). Ceria-Based Mixed Oxide Supported Nano-Gold as an Efficient and Durable Heterogeneous Catalyst for Oxidative Dehydrogenation of Amines to Imines Using Molecular Oxygen. Bulletin of Chemical Reaction Engineering \& Catalysis, 7 (1): 79-84

Permalink: http://ejournal.undip.ac.id/index.php/bcrec/article/view/1257

\section{Introduction}

Imines and their derivatives have long been recognized as basic building blocks for the synthesis of nitrogen heterocycles, especially in the arena of alkaloid synthesis basic building blocks and various synthetic routes for the synthesis of imines are reported. Although the synthesis of aldimines is quite easy by using aldehyde and primary amines, the synthesis of many classes of imines is problematic e.g. ketimines (especially aryl ketimines) [1-3]. The synthesis of ketimines is difficult and requires metal chloride, which is used as dehydrating agent to overcome the competing reverse reaction, but metal chlorides generate $\mathrm{HCl}$ which leads to unwanted side reactions in many systems even in the presence of excess amine $[4,5]$. Stoichiometric methods utilizing strong oxidants such as Swern oxidation have the disadvantage of forming major amounts of side products [6, 7]. So the oxidative dehydrogenation of secondary amines has been explored as an alternative route for the preparation of imines.

The discovery of the catalytic properties of gold nanoparticles is one of the most exciting contributions to catalysis and has led to the renaissance of gold chemistry. Gold based catalysts attracted wide attention ever since Haruta et al., found that supported gold catalysts are highly

* Corresponding Author.

E-mail address: drbaldev1@gmail.com (B. Singh)

Telp: (0191) 2572002,Fax: (0191) 2548607 
active for the oxidation of $\mathrm{CO}$ at temperatures as low as $-73{ }^{\circ} \mathrm{C}$ when deposited as nanoparticles on metal oxides $[8,9]$.The catalytic activity of a gold catalyst does not depend on the size of the gold particles only, but also on the nature of the support material, the preparation method, and the activation procedure [10-13]. Supported gold nanoparticles have attracted considerable attention because of their extraordinarily high activity and selectivity. Support materials like transition metal oxides provide high reactive surface area, thermal stability, higher dispersion of nano-metallic particles and longer catalyst life etc [14]. The discovery that Au clusters dispersed on metal oxide supports act as efficient catalysts for a variety of low-temperature reactions has led to a great deal of study, with the hope that supported $\mathrm{Au}$ clusters may someday replace the less active catalysts currently in use. The use of gold as a catalyst requires careful and unconventional preparation methods for achieving a very small gold particle size. These nano-gold catalysts provide fast reaction rate, high selectivity, and low reaction temperature [15]. The exceptional catalytic capability of supported gold is associated with the size and shape of the nanoparticles, the degree of coordinative unsaturation of the gold atoms, and the interactions between gold and the oxide support [16].

$\mathrm{CeO}_{2}$ is having many beneficial properties in catalysis, such as improving the dispersion of surface metals, store and release oxygen. The later property is expected to help minimizing the pyrophorocity of the metal supported on $\mathrm{CeO}_{2}$ [17]. The two unique features which are responsible for making $\mathrm{CeO}_{2}$ a talented substance for exercise either as a support or as an active catalyst are (a) the $\mathrm{Ce}^{3+} / \mathrm{Ce}^{4+}$ redox couple, with its ability to shift between $\mathrm{CeO}_{2}$ and $\mathrm{Ce}_{2} \mathrm{O}_{3}$ under oxidizing and reducing environments, respectively, and (b) the ease of formation of labile oxygen vacancies[18]. The selectivity of pure $\mathrm{CeO}_{2}$ in oxidation reactions is poor, but the redox chemistry of doped cerium oxides is sensitive to crystal structure defects [19]. $\mathrm{CeO}_{2}$ crystallizes in the fluorite structure in which each cerium ion is coordinated to eight oxygen neighbours, making $\mathrm{CeO}_{2}$ more stable and the reduction of Ce (IV) to Ce (III) is unfavourable. To tackle this problem, one of the best approaches is replacing of another metal/metal oxide into the ceria lattice, thus facilitating the formation of composite oxides. The replacement of cerium ions by cations of different size and/or charge modifies ionic mobility within the lattice resulting in the formation of a defective fluorite structured solid solution. Such modifications in the structure of ceria impart new properties to the catalysts, such as density, ionic conductivity and lattice parameters, improved thermal stability, high catalytic activity $[20,21]$. Inspired by the unique and promising characteristics of ceria-based mixed oxides and solid solutions for various applications, a systematic study was undertaken to understand the of $\mathrm{CeO}_{2}-\mathrm{SiO}_{2}, \mathrm{CeO}_{2}-\mathrm{TiO}_{2}, \mathrm{CeO}_{2}-\mathrm{ZrO}_{2}$ and $\mathrm{CeO}_{2}-\mathrm{Al}_{2} \mathrm{O}_{3}$ mixed oxides as catalyst support. Since, $\mathrm{SiO}_{2}, \mathrm{TiO}_{2}, \mathrm{Al}_{2} \mathrm{O}_{3}$ and $\mathrm{ZrO}_{2}$ are extensively employed as supports as well as catalysts for several applications [22, 23]. We undertook the present investigation to stabilize $\mathrm{CeO}_{2}$ by these oxides. The selected Support materials not only provide high reactive surface area, thermal stability, higher dispersion of nano-metallic particles and longer catalyst life but also act as oxygen exchangers and act as a sponge to capture and release oxygen molecules as per need during the reaction. Herein we report the aerobic oxidative dehydrogenation of amines to imines catalysed by gold supported on ceria based mixed oxides.

\section{Materials and Methods}

\subsection{Catalyst prepration:}

The first step is co-precipitation of metal oxide from metal nitrate solutions. A solution containing $\mathrm{Ce}\left(\mathrm{NO}_{3}\right)_{3} .6 \mathrm{H}_{2} \mathrm{O}(9.314 \mathrm{~g})$ and $\mathrm{SiO}\left(\mathrm{NO}_{3}\right)_{2}(3.6052 \mathrm{~g})$ is treated with a solution of $\mathrm{NH}_{4} \mathrm{OH}$ at constant $\mathrm{pH}$ 9.0 and room temperature with constant stirring using mechanical stirrer. The resulting precipitates were aged at the same temperature for $12 \mathrm{~h}$, then filtered and washed until the removal of nitrate ions. The washed precipitate is dried at 100 ${ }^{\circ} \mathrm{C}$ and calcined under air at $500{ }^{\circ} \mathrm{C}$ for $5 \mathrm{~h}$. The support prepared in this way is Ceria-Silica and is denoted as CS. Similarly we prepared Ceria-titania (CT) using solution containing $8.6112 \mathrm{~g}$ $\mathrm{Ce}\left(\mathrm{NO}_{3}\right)_{3} .6 \mathrm{H}_{2} \mathrm{O}$ and $3.7276 \mathrm{~g} \mathrm{TiO}\left(\mathrm{NO}_{3}\right)_{2}$ : CeriaZirconia (CZ) by using $7.3004 \mathrm{~g} \mathrm{Ce}\left(\mathrm{NO}_{3}\right)_{3} \cdot 6 \mathrm{H}_{2} \mathrm{O}$ and $3.915 \mathrm{~g} \mathrm{ZrO}\left(\mathrm{NO}_{3}\right)_{2}$ and Ceria-alumina (CA) by using $7.9169 \mathrm{~g} \quad \mathrm{Ce}\left(\mathrm{NO}_{3}\right)_{3} .6 \mathrm{H}_{2} \mathrm{O}$ and $6.8432 \mathrm{~g}$ $\mathrm{Al}\left(\mathrm{NO}_{3}\right)_{3} .9 \mathrm{H}_{2} \mathrm{O}$ following the procedure similar to that for the preparation of Ceria-Silica. All solid supports are in the 1:1 molar ratio for $\mathrm{Ce}_{2} \mathrm{O}_{3}: \mathrm{M}_{2} \mathrm{O}_{3}$.

To prepare the catalysts $\mathrm{Au} / \mathrm{CS}, \mathrm{Au} / \mathrm{CZ}, \mathrm{Au} / \mathrm{CT}$ and $\mathrm{Au} / \mathrm{CA}$, aqueous solution of $\mathrm{HAuCl} 4.3 \mathrm{H}_{2} \mathrm{O}$ was precipitated by adding $1 \mathrm{~N}$ aqueous $\mathrm{NaOH}$ at constant $\mathrm{pH}$ and temperature upon mixed metal oxide preliminary suspended in water by mechanical stirring. The resulting precipitate was aged at room temperature for $12 \mathrm{~h}$, then filtered and washed carefully until complete elimination of 
$\mathrm{Cl}$ - ions as detected by using silver nitrate as precipitating agent. The sample was dried at $80{ }^{\circ} \mathrm{C}$ and then calcined at $200{ }^{\circ} \mathrm{C}$.The samples contain $\mathrm{Au} / \mathrm{CS}=1.01, \quad \mathrm{Au} / \mathrm{CZ}=1.15, \quad \mathrm{Au} / \mathrm{CT}=1.79$ and $\mathrm{Au} / \mathrm{CA}=1.34 \mathrm{Wt} \%$ gold as determined by SEM EDEX method using instrument SEM HitachiS520, Japan; Oxford Link ISIS-300 UK with instrument operated at $98 \mathrm{eV}$ resolution. The results were further confirmed by fluorescence Xray crystallography using D8 - Advance, Bruker, Germany Multi Res-Vac34 method. Same method was used to determine $\mathrm{Ce}$ and the other metals which were found to be $\mathrm{Ce}=41.43 \%$ and $\mathrm{Si}=20.32 \%$ in $\mathrm{Au} / \mathrm{CS}, \mathrm{Ce}=42.27 \%$ and $\mathrm{Zr}=18.87 \%$ in $\mathrm{Au} / \mathrm{CZ}$, $\mathrm{Ce}=29.56 \%$ and $\mathrm{Ti}=27.31 \%$ in $\mathrm{Au} / \mathrm{CT}, \mathrm{Ce}=37.48$ $\%$ and $\mathrm{Al}=24.20 \%$ in $\mathrm{Au} / \mathrm{CA}$. The other constituents found were oxygen and minor impurities of $\mathrm{Na}, \mathrm{Ca}$, $\mathrm{V}, \mathrm{Rb}$ and Th etc. The $\mathrm{N}_{2}$ BET surface areas of the powders were determined by $\mathrm{N}_{2}$ adsorption at liquid nitrogen temperature using a Micromeritics Gemini 2360 instrument. Prior to analysis, samples were oven dried at $120{ }^{\circ} \mathrm{C}$ for $12 \mathrm{~h}$ and flushed with Argon gas for $2 \mathrm{~h}$. The surface area thus found was $107 \mathrm{~m}^{2} / \mathrm{g}$ for $\mathrm{Au} / \mathrm{CS}, 101 \mathrm{~m}^{2} / \mathrm{g}$ for $\mathrm{Au} / \mathrm{CA}, 98 \mathrm{~m}^{2} / \mathrm{g}$ for $\mathrm{Au} / \mathrm{CT}$ and $87 \mathrm{~m}^{2} / \mathrm{g}$ for $\mathrm{Au} / \mathrm{CZ}$

\subsection{Catalytic Tests}

After establishing the indispensable nature of the catalyst the conversion of pyrrolidine was chosen as a model reaction to explore the practicability of the proposed methodology (Scheme 1). The reactants used for the present work were of Analytical grade obtained from Fluka chemicals and were used as received. The reactions were carried out in two neck glass reactor fitted with a condenser in one neck and other neck was closed by a rubber septum through which a syringe needle was passed to supply oxygen $\left(\mathrm{O}_{2}\right)$ from oxygen balloon. Reactant $(0.1 \mathrm{mmol})$ was dissolved in toluene $(2 \mathrm{ml})$ in the reactor to which $0.05 \mathrm{~g}$ of catalyst was added. Molecular oxygen was passed through syringe needle and the mixture was kept stirring using magnetic stirrer for $35 \mathrm{~h}$ at $100{ }^{\circ} \mathrm{C}$.

\section{Scheme 1:}<smiles>C1CCNC1</smiles><smiles>COOC(=O)C1CCN(C2=NCCC2)CC1</smiles>

$$
\begin{aligned}
& \mathrm{n}=1,2 \\
& \mathrm{~m}=2,3 \\
& \mathrm{M}=\mathrm{Ti}, \mathrm{Zr}, \mathrm{Si}, \mathrm{Al}
\end{aligned}
$$

the reaction mass was filtered to remove the catalyst powder. Products of these reactions were identified by comparing their mass spectra and GC retention times with those of authentic samples. Yields were determined by GC using authentic samples of the products as calibrants.

\section{Results and Discussion}

In this work, we selected conversion of secondary amines to imines as our model reaction to study the activity of ceria based mixed oxide supported nano-gold catalyst for selective oxidative dehydrogenation using molecular oxygen. After catalyst optimization it was found that $\mathrm{Au} / \mathrm{CT}$ is most active catalyst among the asprepared catalyst so this catalyst was tried for different substrates (Table 1.). The catalyst recyclability was tested up to five reaction cycles and it was found that there is negligible loss in catalytic activity as well as selectivity even up to 5 cycle (Fig. 1). It was also found that loss of catalytic activity can be regained by washing the catalyst with piranha [24] (3:1 concentrated sulfuric acid: $30 \%$ hydrogen peroxide solution). On correlating the catalytic activity with the characterization of the catalysts (table 2.), it is observed that the surface area of the catalysts is not in agreement with catalytic activity but the gold content of the catalysts shows a close concurrence. The increase in catalytic activity with increase in gold content may be due to the increase in the number of active sites. The effect of gold

Table 1: Comparative study of the prepared catalysts

\begin{tabular}{ccccccc}
\hline S. No. & Catalyst & $\begin{array}{c}\text { Gold content } \\
\text { (Wt \%) }\end{array}$ & $\begin{array}{c}\text { Ce Content } \\
\text { (Wt \%) }\end{array}$ & $\begin{array}{c}\text { M Content } \\
\text { (Wt \%) }\end{array}$ & $\begin{array}{c}\text { catalyst surface } \\
\text { area (m²/g) }\end{array}$ & $\begin{array}{c}\text { \% Product } \\
\text { Yield }\end{array}$ \\
\hline 1 & $\mathrm{Au} / \mathrm{CS}$ & 1.01 & 41.43 & 20.32 & 107 & 86 \\
2 & $\mathrm{Au} / \mathrm{CA}$ & 1.34 & 37.48 & 24.20 & 101 & 88 \\
3 & $\mathrm{Au} / \mathrm{CT}$ & 1.79 & 29.56 & 27.31 & 98 & 89 \\
4 & $\mathrm{Au} / \mathrm{CZ}$ & 1.15 & 42.27 & 18.87 & 87 & 80 \\
\hline
\end{tabular}

Note: Reaction conditions: amine, $2 \mathrm{~mL}$ of solvent, catalyst powder $(50 \mathrm{mg}), \mathrm{O}_{2}\left(1000 \mathrm{~mL}\right.$ at $1 \mathrm{~atm}$.) at $100{ }^{\circ} \mathrm{C}$ for 35 $\mathrm{h}$ in toluene 
Table 2: Au/CT catalyzed oxidation of secondary amines to imines

\begin{tabular}{|c|c|c|c|c|}
\hline s. no & substrate & product & $\%$ yield & $\%$ selectivity \\
\hline 1. & & & 89 & $>99$ \\
\hline 2. & & & 85 & $>99$ \\
\hline 3 & & & 78 & $>99$ \\
\hline 4 & & & 71 & $>99$ \\
\hline
\end{tabular}

Note: Reaction conditions: amine, $2 \mathrm{~mL}$ of solvent, catalyst powder (50 mg), $\mathrm{O}_{2}(1000 \mathrm{~mL}$ at 1 atm.) at $100{ }^{\circ} \mathrm{C}$ for $35 \mathrm{~h}$ in toluene

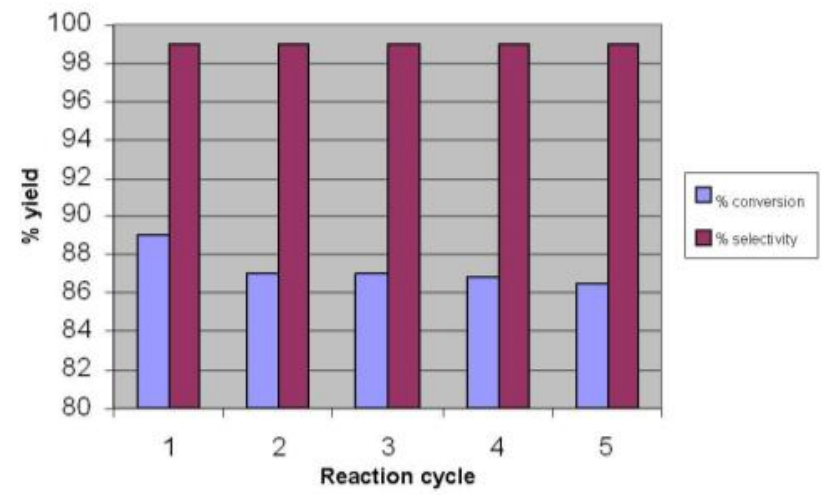

Figure1: Reaction cycles of Au/CT catalyst for the conversion of pyrrolidine to 3,4-dihydro-5(pyrrolidin-1-yl)-2H-pyrrole

particle size is considered to be an important parameter controlling catalyst activity and it is well known that small gold particle size is highly active for selective oxidation because of their much larger surface area to mass ratio. But particle size increases with increasing $\mathrm{Au}$ content from 3\% wt. onwards, because below 3\% wt gold particles are highly dispersed and above this loading cluster size increase and makines only fewer sites available for catalytic activity [25]. In our case the most active catalyst Au/CT has highest gold content containing only 1.79 wt. \% which is much lesser than limiting content (3 wt. \%) among all the asprepared catalysts, so there is no aggregation of gold nanoparticles.

On EDEX and BET surface analysis it is observed Au/CS has highest and Au/CZ has the lowest surface area among the as prepared catalysts, the metal deposition is maximum in $\mathrm{Au} / \mathrm{CT}$ and minimum in Au/CS. Au/CZ although has higher gold content than Au/CS but has lesser activity than latter. Making a look at $\mathrm{CeO}_{2}: \mathrm{MO}_{2}$ ratio it is clear that among all the four supports (or catalysts as a whole) the ratio is lowest for CT $(\mathrm{Au} / \mathrm{CT})$ and highest for $\mathrm{CZ}(\mathrm{Au} / \mathrm{CZ})$, thus it can be said that the catalytic activity is inversely proportional to the $\mathrm{CeO}_{2}: \mathrm{MO}_{2}$ ratio. Ceria-titania combination shows higher catalytic activity among all the four catalysts, which may be due to the lower $\mathrm{CeO}_{2}: \mathrm{MO}_{2}$ ratio, the best fit of $\mathrm{Ti}^{4+}$ into the $\mathrm{CeO}_{2}$ lattice ( $\mathrm{Ti}=1.3 \AA$ and $\mathrm{Ce}=1.1 \AA$ ) and high dispersion capacity of titania [15]. From the above discussion it can be proposed that the catalytic activity of supported gold is affected by $\mathrm{CeO}_{2}: \mathrm{MO}_{2}$ ratio of the catalyst support and its composition also. This may be due to growth of crystalline size of mixed oxide with the increase in ceria content with the result a decrease in metal dispersion on the support, which leads to increase in Au cluster size, hence decrease in surface area of the active component and with the result decrease in catalytic activity [26]. It is reported that $\mathrm{Au}$ foil weakly chemisorbs $\mathrm{CO}$ but is unable to dissociate or molecularly adsorb $\mathrm{H}_{2}$ and $\mathrm{O}_{2}$, however, supported gold nanoparticles adsorb or react with $\mathrm{O}_{2}$ [27] and it is also believed that there are two important factors for the activity of gold nanocluster catalysts, cluster size and a support [28]. Cluster size affects the activity of the catalysts by both surface area and quantum size effect [29] Nano-gold particles-support interactions seem to play an important role in controlling the deposition of gold (amount of gold deposited and size and morphology of gold particles), formation of different surface gold species $\left(\mathrm{Au}^{0}, \mathrm{Au}^{1+}\right.$ and $\left.\mathrm{Au}^{3+}\right)$ and electronic properties of gold particles and, consequently, control the catalytic performance (both the activity and selectivity) of the supported nano-gold catalysts in the reactions [30]. 


\section{Conclusion}

It can be concluded that nano-gold supported on $\mathrm{CeO}_{2}-\mathrm{M}_{\mathrm{n}} \mathrm{O}_{\mathrm{m}}$ is a suitable, efficient, and selective and robust catalyst for the oxidative dehydrogenation of secondary amines to imines in aerobic conditions. It is also observed that support effects the deposition of metal and also the activity of the catalyst. This process is very selective, productive and the catalyst though is costly but it is recyclable which compensates the cost so we can propose that the process is economically beneficial.

\section{Acknowledgement}

We are very thankful to CSIR New Delhi for the financial support.

\section{References}

[1] Li, X.D., Ying, R.L., Xue, L.H.,Yong, G.Z. (1999). Stereoselective reactions with imines, Pure Applied Chemistry. 71(6): 1033-1040.

[2] Gu, X.Q., Chen, W., Morales, D. M., Craig, M.J. (2002). Dehydrogenation of secondary amines to imines catalyzed by an iridium PCP pincer complex: initial aliphatic or direct amino dehydrogenation. Journal of Molecular Catalysis A: Chemical. 189: 119-124.

[3] Friestad, G. K., Mathies, A.K., (2007). Recent developments in asymmetric catalytic addition to $\mathrm{C}=\mathrm{N}$ bonds. Tetrahedron. 63 (12):2541-2569

[4] Amlan, R., Keming, Z., Kissin, Y.V., Cherian, A. E, Coates, G.W., Alan, S.G., (2005). Dehydrogenation of aliphatic polyolefins catalyzed by pincer-ligated iridium complexes Chemical Communication. 3388-3390

[5] Xiaowei, L., Yongming, Z., Long W., Hua, F., Yuyang, J., Yufen, Z. (2008) General and Efficient Copper-Catalyzed Amidation of Saturated C-H Bonds Using N-Halosuccinimides as the Oxidants. Journal of Organic Chemistry. (73): 6207-6212

[6] Zhang, S., Xu, L., Trudell, M. L. (2005) Selective Oxidation of Benzylic Alcohols and TBDMS Ethers to Carbonyl Compounds with $\mathrm{CrO}_{3}-\mathrm{H}_{5} \mathrm{IO}_{6}$. Synthesis 1757-1760.

[7] Chae, S., Yi Lee, W.D. (2009) Efficient Dehydrogenation of Amines and Carbonyl Compounds Catalyzed by a Tetranuclear Ruthenium- $\mu-O x o-\mu-H y d r o x o-H y d r i d e \quad$ Complex. Organometallics. 28(4): 947-949

[8] Wittstock, A., Zielasek, V., Biener, V., Friend, C., M., Bäumer, M. (2010). Nanoporous Gold Catalysts for Selective Gas-Phase Oxidative Coupling of Methanol at Low Temperature. Science 327 (5963): 319-322.

[9] Corma, A., Garcia, H. (2008) Supported gold nanoparticles as catalysts for organic reactions Chemical Society Review, 37: 2096-2126.

[10] Magureanu, M., Mandache, N.B., Hu, J., Richards, R., Florea, M., Parvulescu, V. I. (2007) Plasma-assisted catalysis total oxidation of trichloroethylene over gold nano-particles embedded in SBA 15 catalysts. Applied Catalysis B. Environmental 76: $275-281$.

[11] Jose, A., Sanchez, L., Dimitratos, N., Hammond, C., Brett, G.L, Kesavan, L., White, S., Miedziak, P., Tiruvalam, R., Jenkins, R.L., Carley, A.F., Knight, D., Kiely, C.J., Hutchings, G.J. (2011) Facile removal of stabilizer-ligands from supported gold nanoparticles. Nature Chemistry 3: 551-556.

[12] Shaikhutdinov, S.K., Meyer, R., Naschitzki, M., Umer, M.B., Freund, H.J. (2003) Size and Support Effects for CO Adsorption on Gold Model Catalysts. Catalysis Letters 86 (4): 211-219

[13] Bhargava, S.K., Akolekar, D.B., Foran, G. (2007) Investigations on gold nanoparticles supported on rare earth oxide catalytic materials. Journal of Molecular Catalysis A: Chemical 267: 57-64

[14] Turner, M., Golovko, V.B., Vaughan, O.P.H., Abdulkin, P., Murcia, A.B., Tikhov, M.S., Johnson, B.F.G., Lambert, R.M. (2008) Selective oxidation with dioxygen by gold nanoparticle catalysts derived from 55-atom clusters. Nature 454: 981-983.

[15] Lili, R., Xiaomei, P. (2011) Catalysts used for microwave-assisted TCE decomposition by hydrogen. Catalysis Communications 12(14): 1366-1369.

[16] Liang, W., Xiangju M., Fengshou, X. (2010) Au Nanoparticles Supported on a Layered Double Hydroxide with Excellent Catalytic Properties for the Aerobic Oxidation of Alcohols. Chinese Journal of Catalysis 31(8): 943-947

[17] Vaneet, S., Peter, A.C., Renu, S., James, B.A. (2012) Direct observation of hydrogen spillover in Ni-loaded Pr-doped ceria. Catalysis Today 180 (1, 17): $2-8$

[18] Nikakhtari, H., Hill, G.H. (2005) Enhanced Oxygen Mass Transfer in an External Loop Airlift Bioreactor Using a Packed Bed. Industrial Engineering Chemistry Research. 44 (4): 10671072.

[19] Reddy, E.L., Karuppiah, J., Biju, V.M., Subrahmanyam, C. (2012) Catalytic packed bed non-thermal plasma reactor for the extraction of hydrogen from hydrogen sulfide. International. Journal Energy Research. 37:2204-2209

[20] Bhalla, V., Carrara, S., Stagni, C. Samori, B. (2010) Chip cleaning and regeneration for electrochemical sensor arrays Thin solid Films 518: 3360-3366. 
[21] Enrique, I. (1997) Fischer-tropsch synthesis on cobalt catalysts: Structural requirements and reaction pathways. Studies in Surface Science and Catalysis. 107: 153-162.

[22] Cassinelli, W.H., Feio, L.S.F., Araujo, J.C.S., Hori, C.E., Noronha, F.B., Marques, C.M.P., Bueno, J.M.C. (2008). Effect of $\mathrm{CeO}_{2}$ and $\mathrm{La}_{2} \mathrm{O}_{3}$ on the Activity of $\mathrm{CeO}_{2}-\mathrm{La}_{2} \mathrm{O}_{3} / \mathrm{Al}_{2} \mathrm{O}_{3}$-Supported $\mathrm{Pd}$ Catalysts for Steam Reforming of Methane. Catalysis Letters. 120 (1-2): 86-94.

[23] Meilin, J., Yuenian, S., Changyan, L., Zhaorigetu, B., Shishan, S. (2005). Effect of Supports on the Gold Catalyst Activity for Catalytic Combustion of $\mathrm{CO}$ and HCHO. Catalysis Letters. 99 (3-4 ): 235239.

[24] Bashir, A., D., Mazahar, F. (2011) Supported nano gold a recyclable catalyst for green, solvent free, selective and efficient oxidation of alcohol using molecular oxygen. Orbital - Electronic Journal of Chemistry. 3(2): 89-93.

[25] Umpawan S., Apanee, L., Erdogan, G. (2012) Effect of Gold Loading on $\mathrm{CeO}_{2}-\mathrm{Fe}_{2} \mathrm{O}_{3}$ for Oxidative Steam Reforming of Methanol. World Academy of Science, Engineering and Technology 64: 461- 466
[26] Akkarat, W. (2008) Effect of Cerium Oxide and Zirconium Oxide to Activity of Catalysts. Chiang Mai Journal of Science. 35(1): 156-162.

[27] Miller, J.T., Kopf, A.J., Zha, Y., Regalbuto, J.R., Delannoy , L., Louis , C., Bus , E., van Bokhoven J.A. (2006) The effect of gold particle size on Au$\mathrm{Au}$ bond length and reactivity toward oxygen in supported catalysts. Journal of Catalysis 240: 222-234.

[28] Arcadi, A. (2008) Alternative Synthetic ethods through New Developments in Catalysis by Gold, Chemistry Review. 108: 3266-3325.

[29] Liu, Y., Tsunoyama, H., Akita, T., Tsukuda, T. (2010) Size Effect of Silica-supported Gold Clusters in the Microwave-assisted Oxidation of Benzyl Alcohol with $\mathrm{H}_{2} \mathrm{O}_{2}$. Chemistry Letters. 39: $159-161$

[30] Vasant, R.C., Deepa, K.D. (2009) Supported Nano-Gold Catalysts for Epoxidation of Styrene and Oxidation of Benzyl Alcohol to Benzaldehyde. Topics in Catalysis 52(12): 1677-1687 